


\title{
Maritime Antarctica Soils Studied by Mössbauer Spectroscopy and Other Methods
}

\author{
E. Kuzmann, L. A. Schuch ${ }^{1}$, V. K. Garg, P. A. de Souza Junior ${ }^{2}$, \\ E. M. Guimarães ${ }^{3}$, A. C. de Oliveira and A. Vértes ${ }^{4}$ \\ Institute of Physics, University of Brasilia, 70910-900 Brasília, DF, Brazil \\ ${ }^{1}$ Department of Physics, Federal University of Santa Maria, Santa Maria, RS, Brazil \\ ${ }^{2}$ Department of Physics, Federal University of Espirito Santo, Vitória, ES, Brazil \\ ${ }^{3}$ Department of Mineralogy and Petrology, University of Brasília, Brasília, Brazil \\ ${ }^{4}$ Department of Nuclear Chemistry, Eötvös University, Budapest, Hungary
}

Received 12 September, 1997

\begin{abstract}
Soil samples from the King George Island, Antarctica, have been studied by ${ }^{57}$ Fe Mossbauer spectroscopy, X-ray diffractometry, radiometry, neutron activation analysis and chemical analytical methods. X-ray diffractometry measurements have identified soils containing different volume ratios of quartz, feldspar, chlorite as well as hematite. The difference in the phase composition and in the iron distribution among the crystallographic sites of ironbearing minerals (chlorite, magnetite and hematite) of samples from two different depths was derived from the complex Mössbauer spectra. The differences in the mineral composition, iron distribution, concentration of water soluble salts, $\mathrm{pH}$ and radioactivity of certain radionuclides indicate the occurrence of chemical weathering of minerals.
\end{abstract}

\section{Introduction}

In Antarctica the geological and mineralogical processes are strongly influenced by the presence of ice. Less than $2 \%$ of the continental area is ice free and is accessible for the geological and mineralogical researches. This area is distributed around the periphery of Antarctica. In these areas weathering and soil formation on the glacial deposits and exposed rocks have begun. Based on climate and moisture availability, the soils of Antarctica fall into the following three major soil zones [1], the dry valleys and bare ground on the Trans Antarctic Mountains, the oases of coastal greater Antarctica, and the maritime Antarctic Peninsula. The northern part of the Antarctic Peninsula and the associated islands have a cold moist climate that makes possible the soil formation in the maritime Antarctic region to be different from that which occurs elsewhere in Antarctica
[2-4], The chemical weathering can also be expected to be more active here than in the deserts of the north polar region. Soil studies can contribute to the knowledge of chronology of glacial events by correlating the weathering stages of soils in the Antarctica. A unique feature of Antarctic soils is the diversity of the nature and distribution of salts. Studies of soil sequences may reveal evidence of past variation in climatic conditions and of changes in global atmospheric circulation [1]. The objective of the present work was to investigate soil samples, from the King George Island of the South Shetland Islands in Antarctica.

\section{Experimental and basic ana- lytical results}

The soil samples SOLO1 and SOLO2 were collected near the Brazilian Antarctic Station Comandante Fer-

\footnotetext{
${ }^{*}$ Permanent address: Department of Nuclear Chemistry, Eötvös University, Budapest, Hungary
} 
$\operatorname{raz}\left(62^{\circ} 05^{\prime \prime}\right.$ latitude $58^{\circ} 24^{\prime}$ longitude) in the Keller Peninsula in the King George Island (Fig. 1) of the South Shetland Islands of Antarctica in 1991-1992. The location of the soil samples is depicted in the map of Fig. 2. Samples of SOLO1 and SOLO2 were collected from an area of $10 \mathrm{~cm} \mathrm{x} 20 \mathrm{~cm}$. Samples of SOLO1 were obtained from depths of $\mathrm{O}-5 \mathrm{~cm}$, while samples of SOLO2 were collected from depths of 5 to $10 \mathrm{~cm}$. The thickness of the soil layer on the rock is typically not more than $15 \mathrm{~cm}$ here. The mineralogical and stratigraphical characterization of the rock surrounding is similar to reported ones [5-7] Crustal structure [8], geology [9-17] and environmental parameters [18-21] of the region have been reported, wherein some of the results of the previous Brazilian missions are also summarized. The samples were analyzed by granulometry, and the results are tabulated in Table 1 . The result of the neutron activation analysis is shown in Table 2. Table 3-4 show the analytical data of the soil samples obtained by wet chemical method. Conventional gamma spectroscopy was used to determine the radioactivity of radionuclides in the soils. The result of this analysis is shown in Table 5. X-ray diffractograms of soil samples were recorded either by means of a computer controlled RIGAKU diffractometer using CuKO radiation and a monocromator or by the help of a computer controlled DRON-3 diffractometer using $\mathrm{CuK}_{\alpha}$ radiation and a $\beta$-filter. ${ }^{57} \mathrm{Fe}$ Mössbauer spectra of soil samples were recorded by conventional Mössbauer spectrometers (WISSEL and KFKI) using a scintillation detector in transmission geometry with a ${ }^{57} \mathrm{Co} / \mathrm{Rh}\left(10^{9} \mathrm{~Bq}\right)$ source both at room temperature and temperature of liquid nitrogen $(78 \mathrm{~K})$. Isomer shifts are given relative to the $\alpha$-Fe. The evaluation of Mössbauer spectra was performed by a least-square fitting MOSSWINN [22] program, and the quadrupole splitting distributions were obtained by modified Hesse-Rübartsch methods.

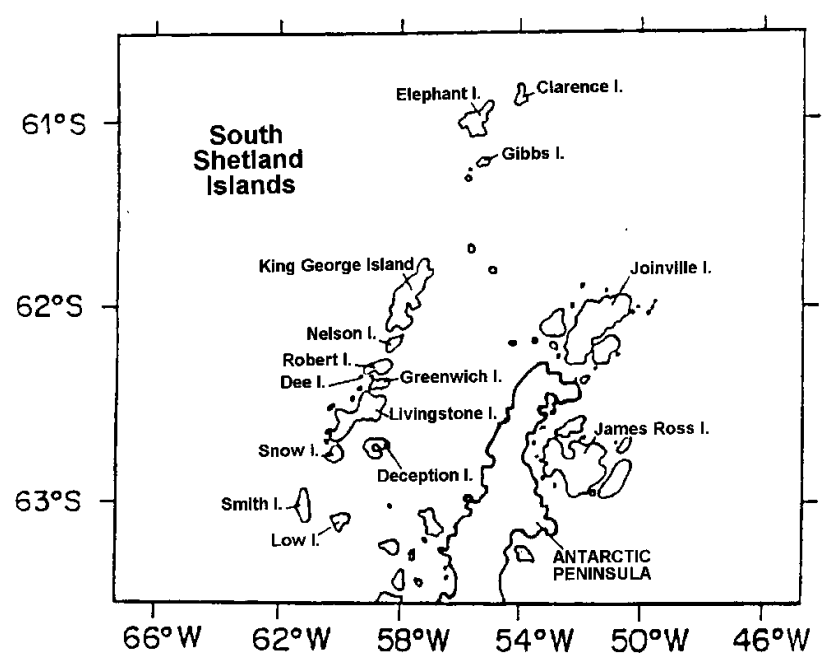

Figure 1. Map of South Shetland Islands.

Table 1 - Granulometric results of soils collected in the Antarctica in 1991-92.

\begin{tabular}{l|c|c|c|c|c}
\hline & $\mathrm{pH}$ & \multicolumn{4}{|c}{ Granulometric composition of soils (\%) } \\
\hline SAMPLE & & $2-0.20 \mathrm{~mm}$ & $0.20-0.05 \mathrm{~mm}$ & $0.05-0.02 \mathrm{~mm}$ & $<0.02 \mathrm{~mm}$ \\
\hline Solo 1 & 5.1 & 28 & 22 & 30 & 20 \\
\hline Solo 2 & 7.0 & 18 & 34 & 15 & 33 \\
\hline
\end{tabular}


Table 2 - Analytical data of neutron activation analysis of soils collected from Antarctica in 1991-92.

\begin{tabular}{|l|c|c|}
\hline Sample Elements & Solo 1 & Solo 2 \\
\hline Sc (ppm) & $21.3 \pm 0.9$ & $25.0 \pm 0.3$ \\
Cr (ppm) & $21.6 \pm 1.1$ & $23.7 \pm 1.4$ \\
Fe (\%) & $\mathbf{5 . 8} \pm \mathbf{0 . 3}$ & $\mathbf{5 . 4} \pm \mathbf{0 . 2}$ \\
Co (ppm) & $22.2 \pm 0.6$ & $23.7 \pm 1.6$ \\
Zn (ppm) & $73.8 \pm 2.5$ & $80.5 \pm 4.2$ \\
As (ppm) & $6.6 \pm 0.5$ & $9.0 \pm 0.7$ \\
Rb (ppm) & $43.9 \pm 3.0$ & $45.3 \pm 3.7$ \\
Sr (ppm) & ND & ND \\
Sb (ppm) & $460 \pm 30$ & $590 \pm 30$ \\
La (ppm) & $25.2 \pm 2.1$ & $25.7 \pm 1.3$ \\
Ce (ppm) & $50.2 \pm 1.5$ & $53.5 \pm 2.7$ \\
Nd (ppm) & $30.2 \pm 2.7$ & $38.7 \pm 4.1$ \\
Sm (ppm) & $5.27 \pm 0.54$ & $6.09 \pm 0.34$ \\
Eu (ppm) & $1.61 \pm 0.06$ & $1.50 \pm 0.06$ \\
Tb (ppm) & $0.70 \pm 0.06$ & $0.77 \pm 0.04$ \\
Yb (ppm) & $2.7 \pm 0.2$ & $2.6 \pm 0.3$ \\
Lu (ppm) & $0.40 \pm 0.03$ & $0.40 \pm 0.02$ \\
Hf(ppm) & $5.7 \pm 0.2$ & $5.8 \pm 0.2$ \\
Th (ppm) & $6.8 \pm 0.2$ & $7.78 \pm 0.07$ \\
U (ppm) & $1.9 \pm 0.1$ & $2.0 \pm 0.5$ \\
Br (ppm) & $0.99 \pm 0.18$ & $0.30 \pm 0.02$ \\
Cs (ppm) & ND & ND \\
\hline
\end{tabular}

Table 3 - Analytical data of soils collected in the Antarctica in 1991-92.

\begin{tabular}{|l|c|c|c|c|c|c|c|c|}
\hline Sample & $\mathrm{P}(\mathrm{ppm})$ & $\mathrm{Mg}^{++}(\%)$ & $\mathrm{Ca}^{++}(\%)$ & $\mathrm{K}^{+}(\%)$ & $\mathrm{Na}^{+}(\%)$ & $\mathrm{C}$ organic $(\%)$ & $\mathrm{N}$ & $\mathrm{C} / \mathrm{N}$ \\
\hline Solo 1 & 167 & 6.1 & 2.1 & 1.1 & 1.88 & 0.95 & 0.08 & 12 \\
\hline Solo 2 & 167 & 7.4 & 2.9 & 1.12 & 2.68 & 0.33 & 0.03 & 11 \\
\hline
\end{tabular}

Table 4 - Analytical data of soluble salts of soils collected in the Antarctica in 1991-92.

\begin{tabular}{c|c|c|c|c}
\hline \multirow{2}{*}{ Sample } & \multicolumn{4}{|c}{ Soluble salts ionic ratio relative to potassium } \\
\cline { 2 - 5 } & $\mathrm{Ca}^{++}$ & $\mathrm{Mg}^{++}$ & $\mathrm{Na}^{+}$ & $\mathrm{K}^{+}$ \\
\hline Solo 1 & 19 & 10 & 10 & 1 \\
\hline Solo 2 & 14 & 10 & 2 & 1 \\
\hline
\end{tabular}

Table 5 - Determination of $\gamma$-radiating radionuclides in soils collected in 1991-92, on the King George Island of South Shetland Islands of Antarctica.

\begin{tabular}{c|c|c|c|c}
\hline \multirow{2}{*}{ Material } & \multicolumn{4}{|c}{ Radionuclides } \\
\cline { 2 - 5 } & Cs-137 & Ra-226 & Ra-228 & K-40 \\
\cline { 2 - 5 } & & BqKg $^{-1}$ & \\
\hline Solo 1 & $2.94 \pm 0.32$ & $20.5 \pm 1.3$ & $22.5 \pm 1.8$ & $383 \pm 21$ \\
\hline Solo 2 & $<0.9$ & $20.8 \pm 1.2$ & $25.4 \pm 2.3$ & $507 \pm 20$ \\
\hline
\end{tabular}




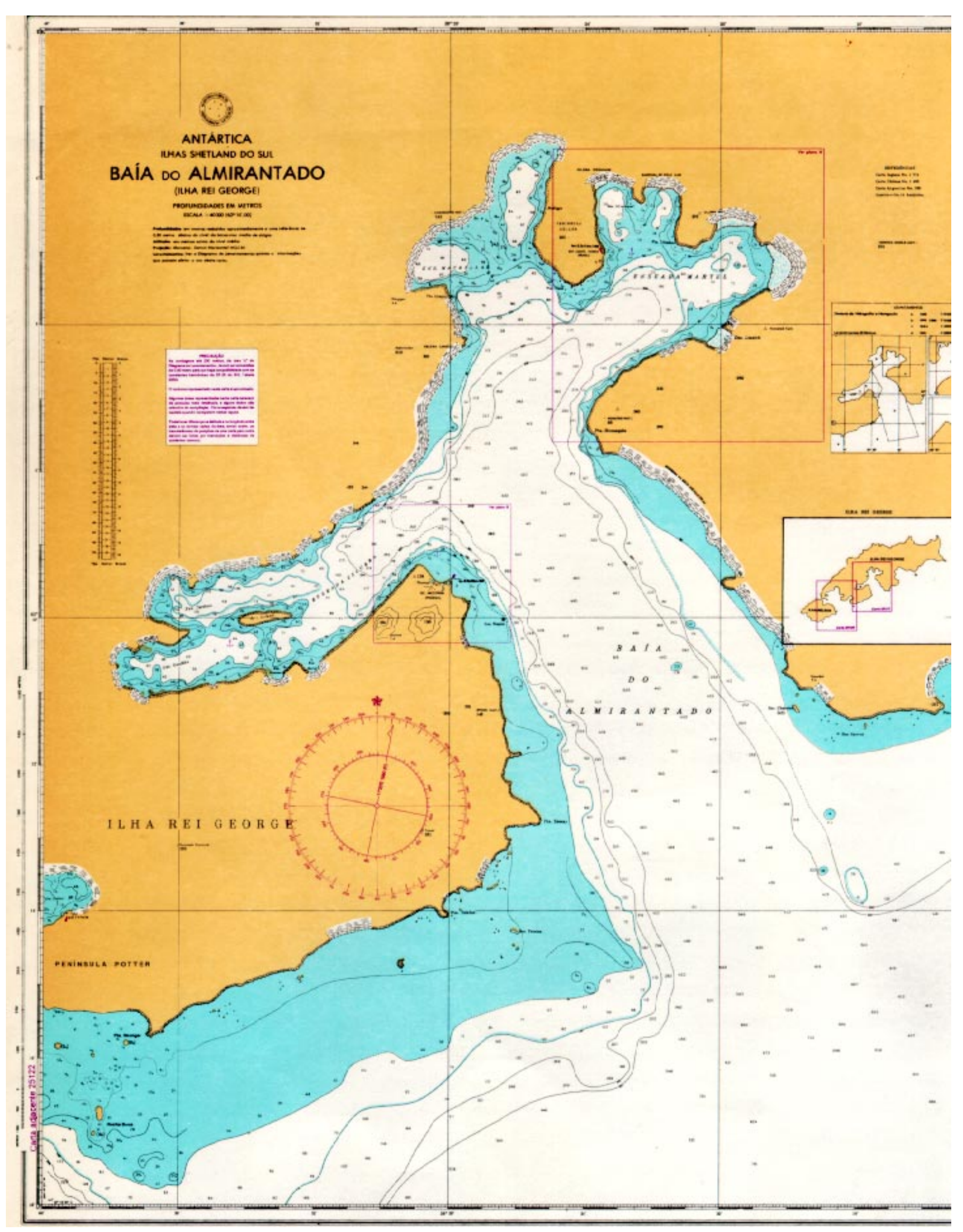

Figure 2. Map of the Bay Aldmiralty on the King George Island in Antarctica. The dot shows the location of the Brazilian Station, from where the soil samples were collected. 


\section{Results and discussion}

X-ray diffractograms of soil samples are depicted in Fig. 3 , and the reflections of quartz, feldspar, chlorite or smectite and hematite can be identified. The lattice spacing of chlorite in SOLO1 is different from that of SOLO2. This indicates that the chlorite in SOLO1 contains significantly more iron than the chlorite in SOLO2. Table 6 shows the normalized integrated intensities of peaks belonging to the identified main phases, giving the estimated occurrence of the main minerals of Antarctic soil samples.

Room temperature Mössbauer spectra of soil samples SOLO1 and SOLO2 are depicted in Fig. 4. These spectra are very complex in nature. The envelop of these spectra shows peaks that lie from $-8 \mathrm{~mm} / \mathrm{s}$ to 8.5 $\mathrm{mm} / \mathrm{s}$. This can be considered as a superposition of magnetically split sextets and a number of paramagnetic subspectra. Several attempts were made to find the optimum deconvolution of these spectra into subspectra. In these cases the spectra recorded at $300 \mathrm{~K}$ and $77 \mathrm{~K}$ were evaluated for the same components of minerals under the corresponding constrains. It was found that the magnetically split part can be very well understood by the decomposition of room temperature spectra into 3 sextets (S1, S2 and S3) whose Mössbauer parameters are in Table 7. Sextet $\mathrm{S} 1$ is attributed to Fe in the hematite, $\alpha-\mathrm{Fe}_{2} \mathrm{O}_{3}$. Since the isomer shift, $\delta$, quadrupole splitting, $\Delta E_{Q}$ and the internal magnetic field, $\mathrm{H}$, are typically characteristic of the hematite [2327 and the isomer shift and the hyperfine field exhibit the expected temperature dependence at $77 \mathrm{~K}$.

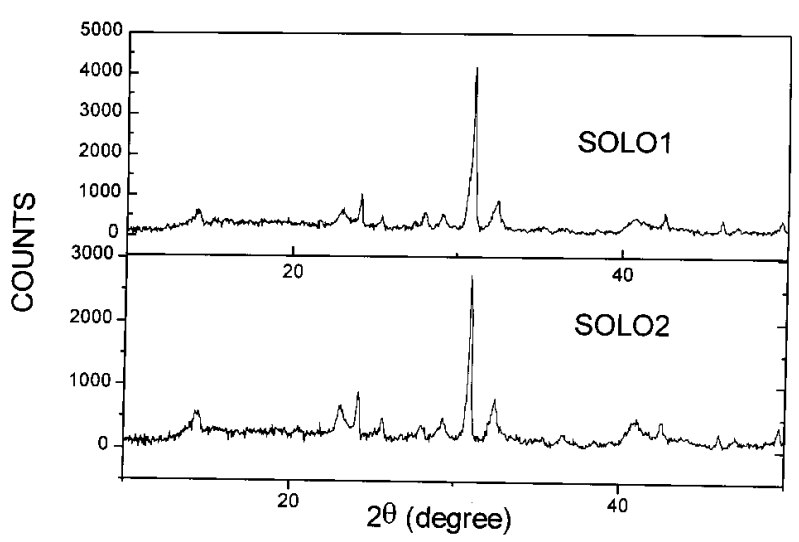

Figure 3. Details of X-ray diffractograms of soil samples collected in King George Island in Antarctica in the years 1991-92.

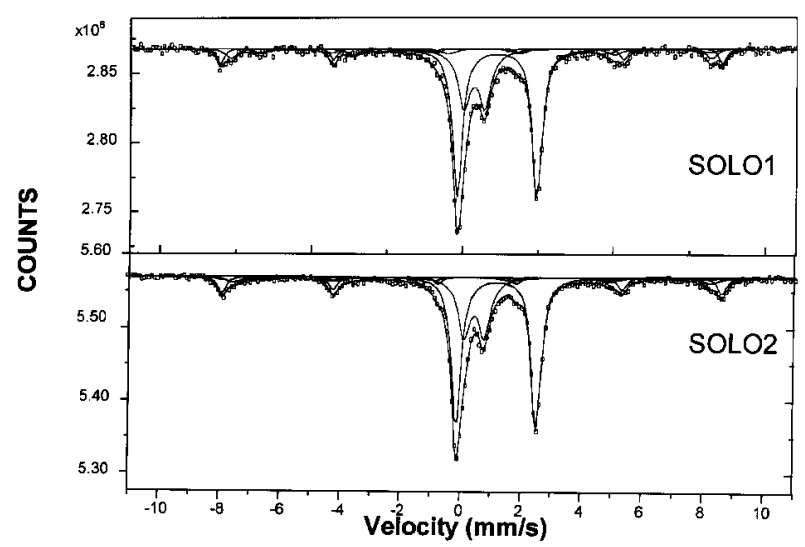

Figure 4. Room temperature Mössbauer spectra of soil samples. (The middle part o the spectra is depicted as decompesed only into a doublet of $\mathrm{Fe}^{3+}$ and a doublet o $\mathrm{Fe}^{2+}$ ).

Table 6 - Result of X-ray diffractometry, (normalized integrated intensities of peaks belonging to the identified main phases).

\begin{tabular}{c|c|c|c|c}
\hline Sample & Quartz & Feldspar & Chlorite & Hematite \\
\hline Solo 1 & 77 & 15 & 7 & 1 \\
\hline Solo 2 & 60 & 24 & 14 & 2 \\
\hline
\end{tabular}


Table 7 - Mössbauer parameters of soils collected from the Antarctica in 1991-1992.

\begin{tabular}{l|c|c}
\hline Table & Solo 1 & Solo 2 \\
\hline A (S1) & $7.8 \pm 0.43$ & $11.7 \pm 0.47$ \\
A (S2) & $6.8 \pm 0.44$ & $6.9 \pm 0.69$ \\
A (S3) & $8.5 \pm 0.57$ & $7.9 \pm 0.73$ \\
A(1.QD) & $25.1 \pm 0.68$ & $23.7 \pm 0.76$ \\
A(2.QD) & $51.8 \pm 0.55$ & $49.8 \pm 0.67$ \\
IS (S1) & $0.38 \pm 0.01$ & $0.40 \pm 0.01$ \\
IS (S2) & $0.25 \pm 0.01$ & $0.31 \pm 0.01$ \\
IS (S3) & $0.69 \pm 0.01$ & $0.71 \pm 0.01$ \\
IS (1.QD) & $0.37 \pm 0.01$ & $0.43 \pm 0.01$ \\
IS (2.QD) & $1.13 \pm 0.01$ & $1.18 \pm 0.01$ \\
MAGN. FIELD & $516 . \pm 0.9$ & $514 . \pm 1.2$ \\
MAGN. FIELD & $494 . \pm 2.4$ & $491 . \pm 3.5$ \\
MAGN. FIELD & $464 . \pm 4.6$ & $451 . \pm 4.8$ \\
Q. S.(S1) & $0.24 \pm 0.02$ & $0.20 \pm 0.02$ \\
Q. S.(1 QD) & $0.69 \pm 0.02$ & $0.66 \pm 0.02$ \\
Q. S.(2 QD) & $2.64 \pm 0.02$ & $2.65 \pm 0.02$ \\
LWS (S1) & $0.26 \pm 0.02$ & $0.35 \pm 0.02$ \\
LWS (S2) & $0.42 \pm 0.07$ & $0.67 \pm 0.11$ \\
LWS (S3) & $0.62 \pm 0.09$ & $1.15 \pm 0.15$ \\
LWS (1.QD) & $0.49 \pm 0.02$ & $0.47 \pm 0.02$ \\
LWS (2.QD) & $0.38 \pm 0.01$ & $0.38 \pm 0.01$ \\
\hline
\end{tabular}

Based upon their Mössbauer parameters hematite [23-27], sextet S2 corresponds to the Fe substituted to the tetrahedral in A site, and the sextet S3 reflects the Fe incorporated into the octahedral B site in magnetite, $\mathrm{Fe}_{3} \mathrm{O}_{4}$. The occurrence of these $\mathrm{Fe}$ microenvironments in hematite and in both cation sites of magnetite are represented by the relative area of these subspectra (Table 8). Since the paramagnetic part of the spectrum is complex and may contain many subspectra, and the absorption percentage can be different, therefore, the conventional spectrum analysis alone cannot lead us to an unambiguous solution. Namely, in most cases of iron bearing paramagnetic minerals, the decomposition of the Mossbauer spectra is generally performed by fitting a few quadrupole split subspectra of Lorentzian lines in the frame of an appropriately chosen model containing the constraints between the Mössbauer parameters of subspectra and the different iron sites. In the model it is considered that the site assignment of the Mössbauer subspectra corresponds well to the distinct cation positions at different crystallographic sites. The result of the evaluation procedure strongly depends, first of all, on the correct knowledge of the number of iron positions that can be distinguished by Mossbauer spec- troscopy. Because of different microenvironments of the same site (e.g. the crystallographic site with different cation neighbors) the number of subspectra can be different from the exact number of crystallographic iron sites which can also be distinguished by the Mössbauer method. The presence of numerous micro-environments can make the conventional evaluation unreliable. For such a case we can use the calculation of quadrupole splitting distribution derived from the Mössbauer spectrum. The correspondence can be given between the peaks of the distribution curve and the different microenvironments. With the help of this method we can distinguish the different micro-environments more reliably compared to the conventional spectrum evaluation.

Fig. 5. shows the distribution curves of $\mathrm{Fe}^{2+}$ and $\mathrm{Fe}^{3+}$ obtained for the SOLO1 and SOLO2 samples using the quadrupole splitting distribution method [22]. Two distributions were calculated simultaneously and ternary polynomial functions were used to give the relation between the isomer shift and the quadrupole splitting. By decomposition of the quadrupole splitting distribution, four peaks (Fig. 5) were found which can be associated with four iron micro-environments. 
Table 8 - Mössbauer parameters of paramagnetic spectral parts of Antarctic soils and of a pure chlorite sample

\begin{tabular}{l|c|c|c}
\hline & & & \\
& Solo1 & Solo2 & Chlorite \\
\hline A(1.QD)\% & $63.1 \pm 1.4$ & $59.6 \pm 1.5$ & $53.5 \pm 1.2$ \\
A(2.QD)\% & $5.1 \pm 0.5$ & $8.0 \pm 0.7$ & $21.3 \pm 0.7$ \\
A(3.QD)\% & $11.2 \pm 0.8$ & $17.8 \pm 0.6$ & $14.5 \pm 0.5$ \\
A(4.QD)\% & $20.6 \pm 0.8$ & $14.6 \pm 0.7$ & $10.7 \pm 0.5$ \\
IS(1.QD) $\mathrm{mm} / \mathrm{s}$ & $1.13 \pm 0.01$ & $1.13 \pm 0.01$ & $1.12 \pm 0.01$ \\
IS(2.QD) $\mathrm{mm} / \mathrm{s}$ & $1.09 \pm 0.01$ & $1.19 \pm 0.01$ & $1.08 \pm 0.01$ \\
IS(3.QD) $\mathrm{mm} / \mathrm{s}$ & $0.41 \pm 0.01$ & $0.42 \pm 0.01$ & $0.42 \pm 0.01$ \\
IS(4.QD) $\mathrm{mm} / \mathrm{s}$ & $0.37 \pm 0.01$ & $0.37 \pm 0.01$ & $0.32 \pm 0.01$ \\
Q.S.(1.QD) $\mathrm{mm} / \mathrm{s}$ & $2.66 \pm 0.02$ & $2.67 \pm 0.02$ & $2.70 \pm 0.02$ \\
Q.S.(2.QD) $\mathrm{mm} / \mathrm{s}$ & $2.31 \pm 0.02$ & $2.35 \pm 0.02$ & $2.34 \pm 0.02$ \\
Q.S.(3.QD) $\mathrm{mm} / \mathrm{s}$ & $0.95 \pm 0.02$ & $0.90 \pm 0.02$ & $0.98 \pm 0.02$ \\
Q.S.(4.QD) $\mathrm{mm} / \mathrm{s}$ & $0.56 \pm 0.02$ & $0.55 \pm 0.02$ & $0.52 \pm 0.02$ \\
\hline
\end{tabular}

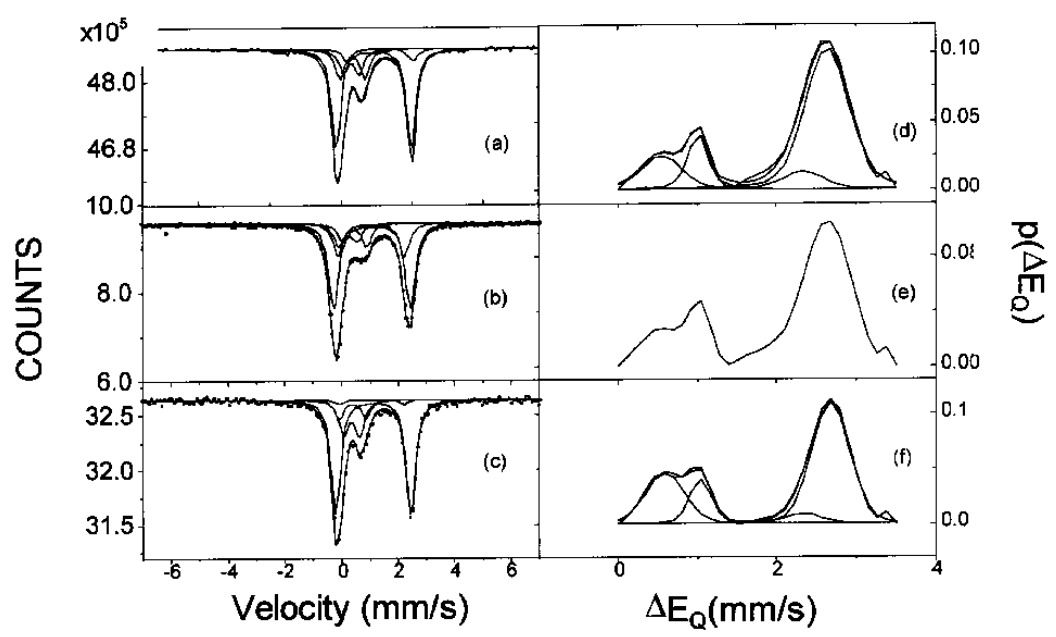

Figure 5. Paramagnetic part of Mössbauer spectra (on the left side) and quadrupol splitting distributions (on the right site) of soil sample SOLO2 (a,d), chlorite (b,e) and soil sample $\operatorname{SOLO1}(\mathrm{C}, \mathrm{f})$.

Based on the results of the quadrupole splitting distribution method, four doublets of Lorentzian lines were used for the conventional decomposition of the obtained Mössbauer spectra of soil samples. By this way, all paramagnetic part of the Mössbauer spectrum could be decomposed into four doublets (D1, D2, D3 and D4); the corresponding parameters are tabulated in Table 9. By comparing the above data, corresponding paramagnetic mineral of the soil samples was determined to be chlorite in both soil samples, (the Mössbauer parameters are in fairly good agreement with those observed with a pure chlorite sample as well as with those re- ported in the literature [24,28]. This conclusion is also in agreement with the X-ray diffractometry, wherein except hematite, only chlorite could be identified as ironbearing mineral.

By comparing 77K Mössbauer spectra with those recorded at room temperature, the presence of superparamagnetic oxides can be excluded. We tried to decompose the paramagnetic part of these spectra into five or six doublets, too, when the parameters were free, or fixed for some known clay minerals. However, even in these cases the previously described analysis gives better results, but a maximum of $2 \%$ of extra phases (kaoli- 
nite, smectite) can not be entirely excluded apart from chlorite. Because our results can be well understood and because iron prefers to accumulate in the chlorite [27] the presence of other silicate phases is neglected. The four doublets in the chlorite Mössbauer spectrum are assigned as follow [23]: D1 represents $\mathrm{Fe}^{2+}$ at M2 site, D2 as reflects $\mathrm{Fe}^{2+}$ at M1 site, D3 belongs to $\mathrm{Fe}^{3+}$ at M1 site and D4 represents $\mathrm{Fe}^{3+}$ at M2 site.

Table 9 - Distribution of iron in Antarctic soils

\begin{tabular}{|c|c|c|}
\hline $\mathrm{Fe}$ & Solo1 & Solo2 \\
\hline In the total sample & & \\
\hline $\mathrm{Fe}^{3+} / \mathrm{Fe}$ & 0.439 & 0.462 \\
\hline $\mathrm{Fe} 2^{+} / \mathrm{Fe}$ & 0.56 & 0.537 \\
\hline $\mathrm{Fe}^{2+} / \mathrm{Fe}^{3+}$ & 1.275 & 1.174 \\
\hline $\mathrm{Fe}^{3+} / \mathrm{Fe}^{2+}$ & 0.784 & 0.852 \\
\hline In the oxides & & \\
\hline $\mathrm{Fe}^{3+} / \mathrm{Fe}$ & 0.188 & 0.226 \\
\hline $\mathrm{Fe}^{2+} / \mathrm{Fe}$ & 0.0425 & 0.0395 \\
\hline $\mathrm{Fe}^{2+} / \mathrm{Fe}^{3+}$ & 4.423 & 5.721 \\
\hline $\mathrm{Fe}^{3+} / \mathrm{Fe}^{2+}$ & 0.226 & 0.174 \\
\hline In the hematite & & \\
\hline $\mathrm{Fe}^{3+} / \mathrm{Fe}$ & 0.078 & 0.117 \\
\hline In the magnetite & & \\
\hline $\mathrm{Fe}^{3+} / \mathrm{Fe}$ & 0.111 & 0.109 \\
\hline $\mathrm{Fe}^{2+} / \mathrm{Fe}$ & 0.0425 & 0.0395 \\
\hline $\mathrm{Fe}^{2+} / \mathrm{Fe}^{3+}$ & 2.612 & 2.759 \\
\hline $\mathrm{Fe}^{3+} / \mathrm{Fe}^{2+}$ & 0.382 & 0.362 \\
\hline $\mathrm{Fe}^{2+}$ in $\mathrm{B}$ site & 0.0425 & 0.0395 \\
\hline $\mathrm{Fe}^{3+}$ in $\mathrm{A}$ site & 0.068 & 0.069 \\
\hline $\mathrm{Fe}^{3+}$ in $\mathrm{B}$ site & 0.0425 & 0.0395 \\
\hline In the chlorite & & \\
\hline $\mathrm{Fe}^{3+} / \mathrm{Fe}$ & 0.246 & 0.241 \\
\hline $\mathrm{Fe}^{2+} / \mathrm{Fe}$ & 0.524 & 0.504 \\
\hline $\mathrm{Fe}^{2+} / \mathrm{Fe}^{3+}$ & 0.469 & 0.478 \\
\hline $\mathrm{Fe}^{3+} / \mathrm{Fe}^{2+}$ & 2.130 & 2.091 \\
\hline $\mathrm{Fe}^{2+}$ in $\mathrm{M} 1$ site & 0.051 & 0.08 \\
\hline $\mathrm{Fe}^{2+}$ in $\mathrm{M} 2$ site & 0.631 & 0.596 \\
\hline $\mathrm{Fe}^{3+}$ in $\mathrm{M} 1$ site & 0.112 & 0.178 \\
\hline $\mathrm{Fe}^{3+}$ in $\mathrm{M} 2$ site & 0.206 & 0.146 \\
\hline Fe in M1 site & 0.163 & 0.258 \\
\hline $\mathrm{Fe}$ in $\mathrm{M} 2$ site & 0.837 & 0.742 \\
\hline FeM1/FeM2 & 0.195 & 0.348 \\
\hline $\mathrm{Fe}^{2+} \mathrm{M} 1 / \mathrm{Fe}^{3+} \mathrm{M} 1$ & 0.455 & 0.449 \\
\hline $\mathrm{Fe}^{2+} \mathrm{M} 2 / \mathrm{Fe}^{3+} \mathrm{M} 2$ & 3.063 & 0.408 \\
\hline $\mathrm{Fe}^{2+} \mathrm{M} 1 / \mathrm{Fe}^{2+} \mathrm{M} 2$ & 0.081 & 0.134 \\
\hline $\mathrm{Fe}^{3+} \mathrm{M} 1 / \mathrm{Fe}^{3+} \mathrm{M} 2$ & 0.544 & 1.219 \\
\hline
\end{tabular}

The difference in the characteristic isomer shift and the quadrupole splitting of doublets reflects differences in the microenvironments of M1 and M2 sites due to the difference in the cation distribution in the soil samples. This is in good correlation with changes found in the lattice parameters of the chlorites in these soils by the help of X-ray diffractometry. Also, significant differences between the relative areas of doublets of SOLO1 and SOLO2 (Table 8) have been found. These reflect different site occupation of iron ions in the two soil samples. The iron distribution data derived from the Mössbauer parameters are shown in Table 9.

Considering the summarized analytical result of Mössbauer spectroscopy (Table 10), it can be concluded that the hematite content is significantly higher in sample SOLO2 than in sample SOLO1. The difference in the phase composition, and the difference of iron distribution between the different crystallographic sites in the minerals of these soil samples reflect the weathering.

Table 10. Distribution of iron in the iron bearing phases derived from the Mössbauer analysis.

\begin{tabular}{c|c|c|c}
\hline & Material & Oxides & Silicates \\
\hline sample & $\mathrm{Fe}_{2} \mathrm{O}_{3} \%$ & $\mathrm{Fe}_{3} \mathrm{O}_{4} \%$ & Chlorite $\%$ \\
\hline Solo1 & $7.8 \pm 0.4$ & $15.3 \pm 1.01$ & $76.9 \pm 1.2$ \\
\hline Solo2 & $11.7 \pm 0.5$ & $14.8 \pm 1.4$ & $735 \pm 1.4$ \\
\hline
\end{tabular}

In desert varnish layers originated from the Upper Taylor Valley of Antarctica weathering has also been observed by Mossbauer spectroscopy [29], however, the iron distribution in the cold desert samples was completely different from the samples of the present investigation, that is, no hematite, magnetite or chlorite could be identified in the desert varnish layer. The iron content of the our soil samples (Table 2) is much higher than that (0.56-2.5 wt\%) found in the cold desert soils in Antarctica [30]

Although, the soils samples from the King George Island have high content of soluble salts, the proportion of calcium, magnesium and sodium relative to potassium is not so high as in the soils originated from the cold desert areas of Antarctica with xerous or ultaxerous climate [31]. The presence of hematite and of relatively high amount of water soluble salts $\left(\mathrm{Mg}^{2+}\right.$ etc.) 


\section{(Augite, hypersthene)}

\section{$\stackrel{\mathrm{O}_{2}, \mathrm{CO}_{2}, \mathrm{H}^{+}}{\longrightarrow}$}

\section{$\mathrm{Mg}^{2+}+\mathrm{Fe}_{2} \mathrm{O}_{3}+\mathrm{CaCO}_{3}+$ Silicates}

Upper Cretaceous-Lower Tertiary volcanic rocks are below the investigated soils [5-7]. Pyroxene andesite (which is the dominant lava), contains phenocrysts of plagioclase, augite, hypersthene and opaque ore as well as varying amounts of ferromagnesian minerals [5-7]. The original ferromagnesian minerals have been altered or completely destroyed, but from the shape of the phenocryst [5] concluded that the original rocks included olivine basalts, hypersthene-augite-andesites and augite-andesites [5]. Apart from the effect of plutonic intrusions [5], characterized by epidote and pyrite mineralization accompanied by widespread albitization of plagioclase, the alterations of these rocks can be associated with weathering.

It has been suggested [5] that pyrite mineralization has taken place in the Keller peninsula. Presence of hematite in our soil samples is in agreement with this suggestion; because, a part of the mineralized pyrite has transformed to a part of hematite after chemical weathering processes.

The correlation of $\mathrm{Na} / \mathrm{K}$ ratio (Table 4 ) with the feldspar content (Table 6) can also indicate that a large part of these cations arises from mineral weathering [1].

The $\mathrm{pH}$ of the upper layer of soil is 5.1 (Table 1) which increases to 7.0 in the lower soil layer which is much lower than that found in the soils in the McMurdo Oasis $(\mathrm{pH}=8)$ or in Inexpressible Island $(\mathrm{pH}=9)$ or Edisto Inlet $(\mathrm{pH}=9)[31]$ where the marine influence is relatively strong. Even in the xerous and ultaxerous soils from Shackleton Glacier the $\mathrm{pH}$ was found to be between 6.0 and 6.5 , which was associated with the effect of acidic salt derived from upper atmospheric circulation [31]. The low, acidic $\mathrm{pH}$ value of soil in our case indicate that the upper atmospheric circulation is an essential source of weathering in the King George Is- land, even by taking into consideration some variations of meteorological parameters?[19]. However, some influence can also be attributed to the organic matter content (Table 3), which decreases at the lower soil layer, where the $\mathrm{pH}$ is neutral. The difference in the $\mathrm{pH}$ value is a indication of different chemical weathering conditions. The higher $\mathrm{pH}$ value gave a favorable condition for the oxidation processes at the lower layers.

The effect of atmospheric circulation is also supported by the result of radiometry measurements on the soil samples. Namely, the Cs-137 activity of SOLO1 sample came from the Cs on the surface originated from the atmospheric circulation [32].

\section{Conclusions}

Soils from the Keller Peninsula, King George Island, Antarctica, were investigated by ${ }^{57} \mathrm{Fe}$ Mössbauer spectroscopy, X-ray diffractometry, radiometry, neutron activation analysis and chemical analytical methods. Quartz, feldspar, chlorite, hematite and magnetite were identified as constituent minerals in the soil samples. The iron distribution among the crystallographic sites of chlorite, magnetite and hematite has been determined. At different depths soils had significant differences in the mineral composition, in the iron distribution among the crystallographic site of chlorite, in $\mathrm{pH}$, in the occurrence of water soluble salts, and in the specific radioactivity of $\mathrm{Cs}$ and $\mathrm{K}$ radionuclides. These results indicates chemical weathering of minerals in this maritime part of Antarctica.

\section{Acknowledgments}

We thank FAP DF (project 104- VKG, and project 106- ACO) and to the Hungarian OTKA Fund (project T014970 - EK) for the financial support. E. Kuz- 
mann thanks the Conselho Nacional de Desenvolvimento Científico e Tecnológico for a foreign visiting research fellowship (project CNPQ VKG 520414/96-9).

\section{References}

[1] G.G.C. Claridge, I. B. Campbell, Physical Geography, Soils, In: Antarctica, Key Environments, Pergamon Press, N.Y. Oxford, Toronto, Sydney, Paris, Frankfurt, pp 62-71 (1984).

[2] R.M.G. O'Brien, J.C.C. Romans, L. Robertson, Bull. Br. Antarc, Surv. 47, 1 (1979).

[3] K. R. Everett, Rep. Inst. Polar. Stud. 58, 14 (1976).

[4] K. Hall, Br Antarc Survey Bull. 79, 17 (1988).

[5] D. D. Hawkes, Sci. Repts. Falkl. Isl. Dep. Survey, 26, 1 (1961).

[6] C. M. Barton, Sci Repts Br Antarc Survey, 44, 1 (1965).

[7] J. L. Smellie, R. J. Pankhurst, M. R. Thompson, R. E. S. Davies, Sci. Repts. Br. Antarc. Survey, 87, 1 (1984).

[8] W. A. Ascroft, Sci. Repts. Br. Antarc. Survey, 66, 1 (1972).

[9] P. E. Baker, I. McReath, M. R. Harvey, M. J. Roolbol, T. J. Davies, Sci. Repts. Br. Antarc. Survey, 78, 1 (1975).

[10] K. Birkenmajer, Stud. Geol. Polon. 64, 7 (1980).

[11] P. C. Kang, M. S. Jing, Petrology and Geologic Structures of the Barton Peninsula, King George Island, Antarctica, In (Antarctic Science: Geology and Biology (Eds. H. T. Huh, B.K. Park, S.H. Lee), Korean Ocean Research, Seoul, 121-135 (1989).

[12] R. A. J. Trouw, A. Ribeiro, F. V. P. Paciullo, Anais da Academia Brasileira Ciências, Suppl. 58, 157 (1986).

[13] E. Valenzuela, F. Herve, Geology of Byers Peninsula, Livingston Island, South Shetland Islan eds, In: Antarctica Geology and Geophysics (R.J. Adie Ed.), Universitatsforlaget, Oslo, p.83-91 (1972).

[14] H. C. Fensterseifer, E. Soliani Jr, M. A. F. Hansen, F. L. Trojan, Ser. Scient. INACH, 38, 29 (1988).

[15] F. L. Trojan, H. C. Fensterseifer, M. A. F. Hansewn, Ser. Scient. INACH, 40, 9 (1990).

[16] M. A. Parada, J. P. Orsini, A. Hurtado, 1. Garido, A. Sina, Ser. Scient. INACH, 36, 9 (1987).
[17] P. R. Dos Santos, A. C. Rocha Campos, R. Trompette, A. Uhlein, M. Gipp, J. C. Simoes, Preliminary report, Pesq. Antarct. Bras. 2, 87 (1990).

[18] Y. Ikeda, L. B. De Miranda, M. Iwai, V. V. Furtado, P. L. Cacciari, Ann. Acad. Sci. Br. Suppl. 117-135 (1986).

[19] I. Fonseca, A. Cavalcanti, Ann. Acad. Sci. Br. Suppl. 172-179 (1986).

[20] E. B. Pereira, D. J. R. Nordeman, M. B. A. Vasconcelos Ann. Acad. Sci. Br. Suppl. 182-186 (1986).

[21] A. M. Paviglione, Y. Ikeda, P. L. Cacciari, Ann. Acad. Sci. Br. Suppl. 150-156 (1986).

[22] Z. Klencsár, E. Kuzmann, A. Vértes, J. Radional. Nucl. Chem. Lett. 210, 105. (1996).

[23] E. Kuzmann, S. Nagy, A. Vértes, T. G. Weiszburg, V. K. Garg, Geological and Mineralogical Application of Mössbauer effect, in Nuclear Methods in Geology (eds. A. Vértes, S. Nagy, K. Süvegh), Plenum Press, NY. 1998.

[24] J. G. Stevens, H. Pollak, Lhi. Zhe, V. E. Stevens, R. M. White, J. L. Gibson, Mineral: Data, Mössbauer Effect Data Center, Univ. North Carolina, Asheville, NC 28814 (1982).

[25] E. Murad, Hyp. Int. 47, 33 (1989).

[26] E. Kuzmann, S. Nagy, A. Vértes, Analytical Application of Mössbauer Spectroscopy, In: Nuclear Methods in Chemical Analysis (Ed Z. Alfassi) N.Y. (1994).

[27] E. Murad, J. H. Johnston, Iron oxydes and oxyhydroxides, In Mössbauer Spectroscopy Applied to Inorganic Chemistry (Ed. G.J. Long), Vol. 2. Plenum, NY. London pp 507-583 (1984).

[28] S. Mitra, Applied Mössbauer Spectroscopy, Physics and Chemistry of Earth Vol. 18, Pergamon, Oxford, N.Y. (1992). p. 197.

[29] J. H. Johnston, C. M. Cardile, Chem Geol 45, 73 (1984).

[30] J. R. Keys, K. Williams, Geochim. Cosmichim. Acta 45, 2299 (1981).

[31] G. G. C. Claridge, 1. B. Campbell, Soil Sci., 123, 377 (1977).

[32] L. A. Schuch, (1993) Cesio-137 e radionuclideos naturais em solos do sul do Brasil e em solos e outras amostras ambientais da Antartica. Doctor Thesis. INPE. (1993). 